\title{
A TRANSIÇÃO TECNOLÓGICA PARA UMA ECONOMIA SUSTENTÁVEL: PRODUÇÃO E CONSUMO, DESAFIOS E RISCOS DE UMA PERSPECTIVA DE DESENVOLVIMENTO SUSTENTÁVEL.
}

\section{Francine Cansi ${ }^{1}$ \\ Liton Lannes Pilau Sobrinho}

\begin{abstract}
Resumo:
O presente estudo tem por objetivo discorrer de forma reflexiva sobre a transição tecnológica para uma economia sustentável, analisando o paradoxo produção e consumo, assim como os desafios e riscos de uma perspectiva de se construir um desenvolvimento sustentável. Através da revisão bibliográfica e o método dedutivo elucidando a problemática proposta, tecnologia e sustentabilidade ambiental podem ser reforçadas mutuamente. As tecnologias desempenham um papel importante na mudança do curso do crescimento econômico rumo à sustentabilidade, fornecendo um modelo socioeconômico alternativo que permitirá que as gerações presentes e futuras desfrutem do possível meio ambiente harmônico e equilibrado.
\end{abstract}

Palavras - Chave: Desenvolvimento; Economia Sustentável; Consumo; Produção; Tecnologia;

\section{TECHNOLOGICAL TRANSITION TO A SUSTAINABLE ECONOMY: PRODUCTION AND CONSUMPTION, CHALLENGES AND RISKS FROM A SUSTAINABLE DEVELOPMENT PERSPECTIVE.}

\begin{abstract}
:
This study aims to reflectively reflect on the technological transition to a sustainable economy, analyzing the production and consumption paradox, as well as the challenges and risks from a perspective of building sustainable development. Through literature review and deductive method elucidating the proposed problem, technology and environmental sustainability can be mutually reinforced. Technologies play an important role in shifting the course of economic growth towards sustainability by providing an alternative socioeconomic

\footnotetext{
${ }^{1}$ Doutoranda em Ciência Jurídica Univali em Dupla Titulação com o Doctorado en Agua y desarollo sostenible del Instituto Universitario del Agua y de las Ciencias Ambientales (IUACA), Alicante/ Espanha. Mestre em Desenvolvimento Regional: Estado Instituições e Democracia-(Unisc/RS-2014). Advogada. Graduada em Ciências Jurídicas e Sociais (Direito) Universidade de Passo Fundo- UPF/RS (2006). Especialista em Direito do Trabalho e Processo do Trabalho, Especialista em Direito Processual Civil. ( francine@ctmadvocacia.com ) https://orcid.org/0000-0002-1434-4862

${ }^{2}$ Pós-doutor em Direito pela Universidade de Sevilha - US. -Espanha. Doutor em Direito pela Universidade do Vale do Rio dos Sinos - UNISINOS (2008), Mestre em Direito pela Universidade de Santa Cruz do Sul - UNISC (2000). Possui graduação em Direito pela Universidade de Cruz Alta (1997). Professor dos cursos de Mestrado e Doutorado no Programa de Pós-Graduação Stricto Sensu em Ciência Jurídica da Universidade do Vale do Itajaí. Professor do Programa de Pós-Graduação Stricto Sensu Mestrado em Direito da Universidade de Passo Fundo.Coordenador do PPGDireito da Universidade de Passo Fundo. (liton@univali.br )
} 
model that will enable present and future generations to enjoy the possible harmonious and balanced environment.

Keywords: Development; Sustainable economy; Consumption; Production; Technology;

\section{Introdução}

As últimas décadas registraram mudanças legislativas significativas à crise ambiental, contudo, ainda está baseada em um modelo voltado para a economia e uma elevada desigualdade social. Para mudar essa realidade são fundamentais uma nova visão centrada na cooperação, em novas concepções de qualidade de vida e a relação dos atores da sociedade com o meio ambiente, de modo que passem a construir o conhecimento e ações efetivas de manutenção e preservação ambiental.

Desta forma, a sustentabilidade importa em mudanças tanto sociais como econômicas, políticas e jurídicas, nas quais necessitam atuar na busca do equilíbrio e da preservação do meio ambiente. E isso impõe uma nova racionabilidade no que concerne igualmente à noção entre o equilíbrio econômico e o poder. Além disso, o despertar de uma cidadania responsável em relação aos direitos e deveres transcende interesses individuais, ponderando sobre o dever de cada um na construção de uma coletividade menos consumista, solidificada nos padrões de desenvolvimento sustentável e equilibrada (ROCHA, 2010; BRASIL, 2018).

Assim, cita-se que a degradação ambiental pode ser descrita como um produto da população, uso desenfreado dos recursos naturais e pelo consumismo excessivo, na qual possibilita um sistema de produção em massa (DAMASCENO et al., 2011). A incapacidade de chegar a um consenso sobre consumo e produção - para acomodar o crescimento econômico, significa que a realização do desenvolvimento sustentável dependerá da capacidade humana em reduzir o impacto ambiental do uso de recursos através de mudanças tecnológicas (PILAU SOBRINHO, 2018).

Nessa visão, os instrumentos econômicos, medidas legislativas e pressões dos consumidores visam a mudanças tecnológicas como reciclagem, minimização de resíduos, substituição de materiais, mudanças nos processos de produção, controle da poluição e uso mais eficiente dos recursos, é um dos desafios do desenvolvimento sustentável. Encontrar novos produtos, processos e tecnologias que sejam ecologicamente corretos, exigirá novas 
tecnologias, inovações tecnológicas e práticas de gestão modernas, bem como mudanças no estilo de vida (LEFF, 2012).

O Fórum Econômico Mundial destaca que a produtividade é o determinante mais importante do crescimento de longo prazo. Independente do efeito preciso sobre as medidas tradicionais de produtividade e crescimento, a medição inadequada é um problema. Em outras palavras, se produz e se consome cada vez mais. Isso sugere a necessidade de uma nova maneira de medir a produção e o consumo, já que não se leva em consideração o valor que está sendo produzido, bem como o que está sendo consumido em todos os setores da economia. É possível afirmar, o crescimento da produtividade estagnou em todo o mundo, particularmente desde a grande recessão, colocando em questão a nossa capacidade de fornecer padrões de vida crescentes para os cidadãos do mundo (PEREIRA; CALGARO, 2016).

Enquanto abundam as discussões sobre o que tem impulsionado a desaceleração da produtividade, uma questão importante é como a aplicação de novas tecnologias aos problemas ambientais existentes deve melhorar a eficiência e, portanto, a mudança dos padrões de consumo e, permitindo que a produção seja mais efetivada com menos?

E, enquanto as discussões de produtividade e medição permanecem teóricas, nada pode ser mais concreto do que o impacto potencial sobre o que é discutivelmente mais fundamental para o nosso senso de valor econômico: consumo e produção.

\section{A tecnologia como processo de mudança para a sustentabilidade}

Ao longo dos tempos, a tecnologia substituiu o esforço humano, que, embora bom para o crescimento da produtividade e para o crescimento geral, é prejudicial para os trabalhadores que perdem seus postos de trabalho. Dada a velocidade e a amplitude das mudanças que agora estão sendo desencadeadas, fica claro que as novas tecnologias mudarão drasticamente a natureza do trabalho em todos os setores e ocupações (PILAU SOBRINHO, 2018). E como a automação inevitavelmente substituirá o trabalho no fornecimento de bens e serviços existentes, a questão principal é quanto tempo isso levará e até onde irá.

Sempre foi o caso de a inovação tecnológica destruir alguns empregos e substituí-los, por sua vez, por novos, em uma atividade diferente e, possivelmente, em um lugar diferente (DAMASCENO et al., 2011). À medida que a inovação tecnológica avança, pode-se esperar 
que as atividades de baixa qualificação sejam progressivamente substituídas por tarefas que exigem criatividade e inteligência social (PILAU SOBRINHO, 2017). E à medida que o mercado de trabalho se torna cada vez mais segregado em segmentos de "baixa qualificação / remuneração" e "alta qualificação / remuneração", as tensões sociais inevitavelmente aumentam. Como enfatizou a Conferências das Nações Unidas na Espanha:

\begin{abstract}
El contexto de la ciencia, la tecnología y la innovación en el que la comunidade internacional comienza a aplicar la Agenda 2030 se caracteriza por una transformación acelerada y profunda impulsada por varias tecnologías en rápida evolución y a menudo convergentes, que, además, están fuertemente vinculadas a la capacidad de reunir, almacenar, transmitir y procesar ingentes cantidades de datos e información. En las economías más avanzadas y en varios países en desarrollo, esos avances tecnológicos están transformando el funcionamiento de los sistemas de producción, así como la función de diversos actores a lo largo de las cadenas de valor y la definición de sectores e industrias ( CONFERÊNCIA DAS NAÇÕES UNIDAS, 2017, p. 2) .
\end{abstract}

Todas as partes interessadas - empresas, governo, sociedade e indivíduos - terão que trabalhar em conjunto para ajustar os sistemas de educação e treinamento que podem continuamente capacitar os trabalhadores. O modelo tradicional de aposentadoria na escola simplesmente não vai mais ser cortado. Isso será particularmente importante se estivermos entrando em uma era em que os trabalhos estão sendo obsoletos muito mais rapidamente do que os novos são criados (DERANI, 1997).

Dado que muitas das fases passadas da revolução industrial ainda não atingiram muitos dos cidadãos do mundo (que ainda não têm acesso à eletricidade, comunicação, telefonia, entre outros), nas últimas décadas, embora tenha havido um aumento na desigualdade dentro dos países, a desigualdade entre os países diminuiu significativamente à medida que os países em desenvolvimento começaram a se recuperar (SETZER, 2007).

Não é apenas um imperativo moral assegurar que as faixas do globo não sejam deixadas para trás; tal cenário também representaria um risco para a estabilidade global por meio de canais como a desigualdade global, fluxos migratórios e até mesmo relações geopolíticas e segurança (SETZER, 2007). Em última análise, os países em desenvolvimento têm a maior lacuna para fechar, mas também podem se beneficiar aprendendo com os erros 
das economias avançadas, saltando para futuros mais prósperos e melhorados tecnologicamente.

Em termos industriais tradicionais, a tecnologia digital e a sustentabilidade ambiental parecem mutuamente exclusivas. Os fatores que os impulsionam não estão relacionados. Uma delas é impulsionada por mudanças tecnológicas radicais trazidas pela Internet das Coisas, pela inteligência artificial (IA) e pela robótica, todas prometendo transformar a manufatura global, os processos industriais e o trabalho. Simplificando, é sobre eficiências (BECK, 2010; SANTOS; PILAU SOBRINHO, 2013).

O outro é impulsionado por uma combinação de clima e degradação ambiental e instabilidade geopolítica, os quais exigem uma nova abordagem que priorize a conservação de recursos e a governança ambiental - e, em particular, esforços redobrados para descarbonizar a atmosfera (BECK, 2010). As empresas reconhecem cada vez mais que será impossível atender à crescente demanda mundial por produtos e serviços puramente por meio de um aumento linear na produção e no consumo. As pessoas não conseguirão enfrentar os desafios ecológicos e sociais do dia sem a inovação do modelo de negócios fundamental. Além disso, práticas insustentáveis como a liberação de emissões tóxicas não podem mais ser ocultadas (PEREIRA; PEREIRA; PEREIRA, 2009).

E visualiza-se além: sem a tecnologia digital, é difícil para as empresas mitigar seu gerenciamento ecológico, sem um entendimento completo da sustentabilidade, e as práticas sustentáveis deve estar na vanguarda do pensamento estratégico de qualquer negócio - como uma forma de se diferenciar e obter viabilidade de longo prazo entre os clientes, os reguladores e as comunidades onde as empresas operam (PEREIRA; CALGARO; PEREIRA, 2016). Na verdade, pode até ser essencial.

As tecnologias combinadas com a sustentabilidade poderiam ser usadas para beneficiar o meio ambiente, incluindo a previsão otimizada do sistema de energia; infraestrutura de demanda-resposta em transporte, por exemplo; análise e automação para planejamento urbano inteligente; previsão climática local, nacional e internacional; manejo de culturas; e monitoramento e transparência da cadeia de suprimentos. De fato, os frutos mais acessíveis aqui podem se concentrar em cadeias de fornecimento transparentes e no fornecimento sustentável de matérias-primas (TRIGUETO, 2008).

No passado, não era incomum as empresas saberem pouco sobre seus ativos ou produtos depois de terem sido fabricados e vendidos. Assim, uma grande quantidade de 
resíduos foi involuntariamente incorporada ao ciclo de fabricação e consumo (BAUMAN, 2010). Mas, usando a tecnologia digital, como a etiquetagem eletrônica, as empresas podem começar a coletar dados sobre a demanda, o uso e o ciclo de vida dos produtos para benefícios de "economia circular". Uma economia circular é aquela em que os produtos são fabricados e os serviços prestados com foco na reutilização de materiais e a dependência de recursos renováveis, em benefício do meio ambiente (CLARO; CLARO; AMANCIO, 2008).

O que é frequentemente conhecido como indústria sustentável, engloba uma série de melhorias digitais que podem ser aplicadas a empresas de manufatura. Uma melhor captura de dados de ativos deve permitir que fabricantes e usuários entendam melhor o ciclo de vida de seus produtos. Tal entendimento traz muitos benefícios para os negócios, mas também pode ser usado para aumentar a eficiência no uso e incentivar a reutilização ou remanufatura de ativos ao final de sua vida útil normal (CLARO; CLARO; AMANCIO, 2008).

Essa ação também aborda questões de valor para o cliente, lidando com a crescente preocupação com a sustentabilidade corporativa nas quais precisarão priorizar a produção de melhores resultados para os consumidores. No entanto, por mais convincente que essa interação entre tecnologia digital e sustentabilidade possa parecer, não é uma panaceia (BAUMAN, 2010).

Embora a tecnologia digital e a sustentabilidade se reforcem mutuamente, nem sempre se combinam facilmente. Por todo o enorme potencial que a tecnologia digital oferece para a construção de um planeta sustentável para as gerações futuras, ela também representa riscos de curto e longo prazo (PEREIRA; CALGARO; PEREIRA, 2016).

Esse desenvolvimento levanta sérias questões sobre o crescimento econômico de consumo e produção, e, como isso afeta a capacidade dos países em reduzir o impacto ambiental. Provavelmente, de maneira mais visível, a crescente dependência de algoritmos para executar tarefas, moldar escolhas e tomar decisões; e a redução gradual do envolvimento humano em muitos processos. Juntos, esses elementos levantam questões relacionadas à justiça, responsabilidade e respeito pelos direitos humanos (SERRA; MORAES, 2007).

Acredita-se que a aplicação da tecnologia digital requer uma estratégia de sustentabilidade muito mais equilibrada, que entenda e considere seus impactos econômicos e sociais (SERRA; MORAES, 2007). De fato, a opinião consensual sobre as contribuições da tecnologia digital para a economia circular pode estar perdendo uma compreensão de seu impacto na sociedade. Isso não pode ser ignorado, pois as empresas desempenham o seu papel 
na direção dos 17 objetivos de desenvolvimento sustentável das Nações Unidas (ODS 17) definidos em 2015.

E embora a tecnologia apresente oportunidades transformadoras para enfrentar os desafios ambientais da Terra, ela também tem a capacidade de acelerar a degradação do meio ambiente. Se a sociedade quiser desenvolvê-la de forma "segura", é necessário garantir que se alinhe aos valores da humanidade, minimizando os recursos extraídos, criando biodiversidade, neuro-diversidade e inclusão nas comunidades.

\section{Os paradoxos do desenvolvimento tecnológico sustentável}

Os efeitos da tecnologia estão por trás dos desafios globais do início do século XXI. Se por um lado, desde o Iluminismo, a tecnologia, especialmente a baseada na ciência, ofereceu a promessa de um mundo melhor através da eliminação de doenças, pobreza e materiais, melhorias nos padrões de vida. Por outro lado, a extração de recursos, as emissões de materiais perigosos e a poluição do ar, da água e do solo criaram condições para catástrofe ambiental sem precedentes, levando aos danos irreversíveis a biosfera (SERRA; MORAES, 2007).

Enquanto o futuro pode prometer uma vasta aceleração da tecnologia e inovação, a escala e o impacto da degradação ambiental podem refletir essa vasta aceleração também. Um paradoxo relacionado é que, apesar da revolução tecnológica em curso, a maioria da população mundial ainda vive em extrema pobreza sem habitação, água, alimento e energia, atormentada por doenças que poderiam ser facilmente curadas se água limpa e drogas simples foram disponibilizadas (STELZER, 2007).

Alguns países, como China, Índia, Coréia, Taiwan, Cingapura e, até certo ponto, o Brasil seguiu suas próprias trajetórias tecnológicas. No entanto, para grandes populações na África, Ásia e América Latina, os benefícios da tecnologia permanecem distantes, mesmo com células fotovoltaicas, telefones celulares e Internet, apresentam nos segmentos da sociedade condições abaixo da pobreza.

Ao mesmo tempo em que o poder público na África, investia no avanço tecnológico, foi elaborado conjunto de legislações que viriam, posteriormente, comprometer a própria expansão da base de inovação nacional. Diferentemente do paradigma utilizado até então, o novo marco regulatório para o setor parte do 
pressuposto sistêmico de produção científica, não mais limitado às áreas de Ciência e Tecnologia, mas visando abranger temas mais próximos à realidade da maioria da população, bem como reestruturar a mão de obra especializada, os esquemas de interação entre setor privado e governo e modernizar os mecanismos de financiamento à pesquisa. Esse sistema passou a ser o marco estratégico a partir do qual o setor seria desenvolvido com vistas a proporcionar melhoria das condições de vida de todo o povo sul-africano, na qual, não produziu resultados (BRASIL, 2002, p. 14-15).

As contradições persistentes entre uma vida melhor criada e apoiada pela tecnologia para poucos, o aumento da degradação ambiental e a pobreza persistente, faz com que a grande maioria exija uma exploração mais profunda e compreensão da natureza e da tecnologia, relacionando-a com a coletividade, especialmente para uma sociedade sustentável. No contexto do esforço para catalisar uma sociedade global sustentável, mudanças profundas na cultura, valores, padrões de consumo, governança, negócios e instituições precisam urgentemente serem previstas (DERANI, 1997).

Assim, a sustentabilidade no domínio de sua concretização implica uma equidade social entre gerações, e que a mesma se amplie às gerações vindouras. Nesse debate, existe a transição entre a questão da responsabilidade e do compromisso social que abrange todos. São temas que permeiam a questão ética e política no campo da participação ativa da sociedade. Para isso, é imperativo compor um sujeito que perceba a sustentabilidade com sentido e composição para sua vida e das gerações futuras (PILAU SOBRINHO, 2017).

É necessário repensar subjetivamente os paradigmas, instituído pelo capitalismo, na qual nunca depositou uma visão que incorporasse a vida e o respeito às diferenças social e cultural. Deste modo, é apropriado aqui debater que o advento da tecnologia culminou nos saberes exteriorizados, tornando-se uma forma de controle econômico e sócio-político dos países que os detêm (SERRA; MORAES, 2007).

Ao direcionar essa discussão para o âmbito do desenvolvimento sustentável é presumível aventurar-se em afirmar que são raros os países que alcançarão uma economia que possibilite a sustentabilidade. Por certo, como afirma Stelzer (2007), foram os países com maior desenvolvimento, os responsáveis pela degradação ambiental, por meio legal e ilegal da extração de seus recursos e dos recursos naturais dos países pobres. Responsáveis estes, pela transformação desenfreada dos ecossistemas. E, apesar do discurso atual ser voltado à tecnologia e inovação, o principal instrumento para reparar os problemas causados pela exploração descomedida dos recursos naturais e para concretizar de fato o desenvolvimento sustentável, poucos países têm acesso a elas (BAUMAN, 2010). 
Diante disso, as discussões aqui presentes remetem ao velho problema de quem está no controle, reprimindo e definindo a via de hegemonia do modelo econômico e político, visando saídas para persistir no poder. Tal discurso da sustentabilidade na orientação do desenvolvimento econômico, trazem questões: voltadas a finalidade científica da era tecnológica para a efetivação do desenvolvimento sustentável (TRIGUEIRO, 2008).

A contemporaneidade impulsiona para o mundo da informação e do conhecimento, constituído por informações e contribui de maneira determinante para o modelo de desenvolvimento econômico e social de caráter eminentemente capitalista. Já, a ciência implica a relação epistemológica que o homem constitui com o conhecimento cientifico mais eficaz da realidade advindo da previsibilidade dos fenômenos e, com isso, aumenta o poder de domínio sobre a natureza (BECK, 2010).

Esse poder é consolidado, a partir da vinculação entre ciência e tecnologia, do saber científico e do avanço do conhecimento que endossa o progresso sustentado pela instrumentalização racional na condução da humanidade para o desenvolvimento sustentável (TRIGUEIRO, 2008).

Diante disso, afirma-se é possível pensar como pressuposto da autonomia, como único instrumento capaz de convergir em um verdadeiro e justo crescimento econômico sustentável pelo viés de mudanças no consumo e na produção, de forma efetivamente sustentáveis. Com isso, o desenvolvimento sustentável pressupõe a liberdade política, econômica e social de todos, levando em consideração suas especificidades (SANTOS; PILAU SOBRINHO, 2013).

Nesse sentido, os segmentos econômicos para a obtenção do avanço tecnológico impõem aos Estados, a necessidade das sociedades civis emergentes o direcionamento e a consciência da importância do desenvolvimento sustentável para a manutenção da vida do meio ambiente, e das gerações futuras (DAMASCENO et al., 2011).

Nesse viés, faz-se necessário um olhar sobre a produção e consumo, considerando a inovação tecnológica como ferramentas e instrumentos para melhorar a capacidade humana de moldar a natureza e resolver problemas de degradação, economia e sociedade, conhecimento, baseado em observações, hipóteses e generalizações sobre as leis naturais relativas ao comportamento sustentável. 


\section{A construção do consumo e produção sustentáveis na era tecnológica}

Nos últimos 50 anos, a população global consumiu mais bens e serviços do que o total combinado de todas as gerações anteriores. Esse consumo estimulou o crescimento econômico, e consequente degradação ambiental mesmo melhorando a qualidade de vida de muitos. No entanto, os padrões de consumo diferem significativamente entre nações desenvolvidas e em desenvolvimento (PEREIRA; CALGARO; PEREIRA, 2016).

Damasceno et al. (2011) observa que o quinto país mais rico do mundo, responde por $86 \%$ do consumo, enquanto o quinto mais pobre responde por cerca de $1 \%$ do consumo. A humanidade está enfrentando uma série de crises globais graves como as mudanças climáticas, privação generalizada e necessidades humanas não satisfeitas, e aumento da desigualdade e exclusão social.

Cada uma dessas situações tem o potencial de desencadear inquietação social e, ao mesmo tempo, ameaça minar a democracia e a paz. Eles também estão intrinsecamente ligados uns aos outros, e tais interconexões provavelmente amplificarão em riscos relacionados. Esses problemas precisam ser compreendidos e tratados de maneira abrangente, refletindo sua natureza sistêmica (DERANI, 1997).

Os desafios acima mencionados estão, de várias formas, intimamente associados ao consumo e produção de bens e serviços da sociedade. A crise ecológica - o uso excessivo de recursos naturais, a poluição e a ruptura do processo natural do planeta - é um reflexo direto do que é produzido e consumido e em quais quantidades. As crises humanitária e social são em grande parte devido ao acesso desigual à energia e aos materiais e oportunidades para satisfazer necessidades e desejos. Lidar com sucesso com essas terríveis ameaças, portanto, requer uma reestruturação de como nós produzimos e consumimos (PEREIRA; CALGARO; PEREIRA, 2016).

O consumo sustentável não pode ser conceituado sem a devida consideração de como a sociedade contemporânea é econômica e institucionalmente organizada. A partir das perspectivas da ciência política, gestão, e as teorias da prática social identificam os aspectos sistêmicos que moldam, ou pelo menos, reconhecer essa situação, implica na mudança sistêmica de comportamentos e uma mudança consistente com os objetivos do consumo sustentável (ROCHA, 2010). 
Os atuais padrões de consumo insustentáveis estão destruindo o meio ambiente; esgotando os estoques de recursos naturais; distribuição de recursos de maneira desigual; contribuindo para problemas sociais como a pobreza; e dificultando os esforços de desenvolvimento sustentável. Concentrando-se no lado da demanda, o consumo sustentável complementa práticas e realizações de produção sustentáveis (PINTO; BATINGA, 2016).

O consumo sustentável requer uma abordagem multidisciplinar e multinacional. As principais barreiras ao consumo sustentável incluem: falta de conscientização e treinamento; falta de apoio da comunidade, governo e indústria; relutância em incluir os verdadeiros custos ambientais e sociais no preço de bens e serviços; padrões de pensamento e comportamentos insustentáveis e arraigados; e falta de produtos e serviços sustentáveis alternativos (ROCHA, 2010).

A abrangência desse paradigma tanto de produção como de consumo, que se fundamenta, de fato, no objetivo de desenvolvimento econômico, e tem alcançado todos os recursos naturais, de forma predatória, sem acolher aos desígnios da eficácia e da racionabilidade que deveriam, no mínimo suprir e manter a sustentabilidade. Requer ação atempada e concertada do governo, empresas e consumidores. Seu objetivo final tem que ser um mundo com maior consciência dos impactos ambientais e sociais, em que as necessidades de auto realização da população não sejam atendidas com níveis de consumo cada vez mais altos (CONTE; BOFF, 2013).

O padrão de consumo (e produção) é problemático diante de um planeta com recursos finitos. Se houver continuidade do consumindo e a produção exagerada como se faz atualmente, chegará o dia em que a Terra não poderá mais fornecer os recursos necessários para satisfazer os desejos ilimitados do ser humano (FREITAS, 2012).

Outra faceta do estado da humanidade é que, enquanto a sociedade progride no combate à pobreza, e por comunidades mais seguras, o custo para o planeta, representa um impacto gigantesco no meio ambiente. Portanto, considerando: 1) a aspiração humana ilimitada e aumentando a renda disponível; 2) a necessidade de suprimir a pobreza e proporcionar padrões de vida decentes para toda a população (crescente) do mundo e, 3) o impacto da atividade humana na terra, faz indispensável encontrar soluções e compromissos. Em outras palavras, a fim de assegurar que o desenvolvimento sustentável, aborde a necessidade de toda a humanidade enquanto remove o estresse excessivo no planeta, 
a adoção de padrões sustentáveis de consumo e produção é um imperativo (CANCLINI, 2001; SANTOS, 2008; VOLKMER, 2011).

A vida sustentável, no seu sentido mais verdadeiro, só pode ser alcançada se houverem mudanças radicais a consciência de todos. Seja verificando o crescimento populacional ou deixando de lado todos os desejos e necessidades (além das necessidades básicas), debatendo os papéis da economia e da tecnologia ou repensando os sistemas e instituições atuais, e, na ausência de uma mudança tão transformadora em nosso paradigma, a adoção da prática do Consumo Sustentável e da Produção é uma solução viável e imediata para aliviar parte de nossa pressão sobre o planeta (SANTOS, 2008).

Ao promover uma sociedade para o consumo sustentável, com ênfase na tecnologia como instrumento para a sustentabilidade, deve ser considerada na economia, as dimensões sociais e éticas dos produtos, serviços e bens, como eles são produzidos, bem como seus impactos ecológicos. Nesse sentido, promover o consumo para o desenvolvimento sustentável, depende da obtenção de crescimento econômico compatível com as necessidades ambientais e sociais (PORTILHO, 2010).

A promoção deste consumo é igualmente um importante limitar as externalidades ambientais e sociais, bem como para fornecer mercados para produtos sustentáveis. Em outros termos, como resultado de políticas e iniciativas de consumo sustentável voltam-se a complexidade e variedade de ferramentas tecnológicas e iniciativas governamentais voltadas ao consumo sustentável, na qual sublinham a necessidade de programas mais integrados, bem como a institucionalização do consumo sustentável como estratégias de desenvolvimento das sociedades (CANCLINI, 2001).

A interpretação convencional sobre o consumo, é que quanto menos se consome, inexoravelmente, leva-se à desaceleração econômica e colapso dentro do sistema existente é imprescindível elaborar cada vez mais, e de forma inovadora uma economia voltada a conscientização sustentável do consumidor, para expandir a realidade dos os limites planetários da Terra (SANTOS, 2008).

Nessa argumentação, exige-se garantias para as redes de produção e distribuição, que venham operar de acordo com os princípios responsabilidade, transparência e sustentabilidade. Consequentemente, devem ser considerados, novos sistemas de provisionamento que contribuam significativamente para reduções nos efeitos adversos da produção e consumo (SANTOS, 2008). 
Exemplo disso, o Objetivo 12, da Agenda 2030, introduziu a gestão eficiente dos recursos naturais de forma responsável, instituindo a concepção da ecoeficiência, a produção limpa e outras abordagens gerenciais destinadas a harmonizar os objetivos ambientais, a economia, a sociedade e a governança. Sua implementação ajuda a alcançar planos de desenvolvimento globais, reduzir custos econômicos, ambientais e sociais futuros, fortalecer a competitividade econômica e reduzir a pobreza (PINTO; BATINGA, 2016).

Embora tenham sido feitos alguns progressos no consumo e na produção responsáveis, isso foi insuficiente. De fato, o ODS 12 foi sinalizado como um dos quatro ODS que está mais em risco de não ser atendido até 2030. A atenção é particularmente necessária para limitar o consumo através da inovação do modelo de negócio. Tal objetivo de sustentabilidade não pode ser atendido se os modelos de negócios continuarem a depender do aumento do consumo (PEREIRA; CALGARO; PEREIRA, 2016).

As metas de sustentabilidade, baseadas na ciência e tecnologia são "fundamentadas no conhecimento científico de como os impactos humanos afetam os recursos vitais". Eles são particularmente relevantes para ajudar as sociedades a determinar se estão ou não gerenciando seus impactos dentro de limites ecológicos e sociais (PINTO; BATINGA, 2016).

Com base nesse objetivo amplo, o conceito se tornou associado a uma ampla variedade de abordagens, incluindo: consumir de forma diferente, usar produtos com menos recursos, passar de produtos materiais para serviços imateriais, economizar energia, compartilhar o uso de produtos com maior longevidade (DAMASCENO et al., 2011).

Adicionado a isso, os padrões sustentáveis de consumo e produção representam características de articulação às questões como igualdade, ética, conservação do meio ambiente e cidadania, ressaltando a relevância de ações práticas, tanto no campo do Estado como da coletividade, como condutores de um processo que, apesar de agregar valores subjetivos, profere ações na dimensão global (PINTO; BATINGA, 2016).

A ênfase está em consumir de forma diferente - dando prioridade a produtos e serviços com menores impactos ambientais e sociais associados em comparação com alternativas convencionais (DERANI, 1997). Tais práticas têm como objetivo levar a mudanças dentro do atual sistema econômico e estimular o crescimento sustentável.

Com base nisso, retomando o consumo consciente observa-se que possibilitaria o desfrute de mais qualidade de vida e menor custo ambiental, por meio de melhor maneira de "eleger e utilizar" por parte da sociedade a orientação de um padrão apropriado de consumo 
voltado para o bem-estar, que é influenciado por aspectos civis, culturais e religiosos, bem como o meio de manter o ambiente saudável (DAMASCENO et al., 2011).

Como o consumo e a produção sustentáveis visam "fazer mais e melhor com menos", os ganhos líquidos de bem-estar das atividades econômicas podem aumentar reduzindo o uso de recursos, degradação e poluição ao longo de todo o ciclo de vida, aumentando a qualidade de vida. Também precisa haver um foco significativo na operação da cadeia de suprimentos, envolvendo todos, desde o produtor até o consumidor final (PEREIRA; CALGARO; PEREIRA, 2016).

Um sistema de consumo sustentável como "um sistema que liga bens e serviços ambientais, indivíduos, famílias, organizações e estados através de ligações nas quais energia e materiais são transformados, utilidade é derivada e relacionamentos (por exemplo, transações de dinheiro ou informação e exercício de influência e controle social)". Entendido nestes termos, como um sistema de consumo e produção sustentáveis é aquele em que a transformação de energia e materiais mantém ou melhora o bem-estar humano (ou utilidade) sem esgotamento ou degradação irreversível dos recursos ambientais (PEREIRA; CALGARO; PEREIRA, 2016, p. 126).

Uma perspectiva de sistemas permite a consideração de formas alternativas de governar o fornecimento de energia e materiais não apenas em pontos específicos de atividade, como em mercados ou através de acordos comerciais, mas ao longo de cadeias de suprimentos e resíduos (DAMASCENO et al., 2011).

Tal perspectiva também traz à tona questões de justiça e justiça social, a necessidade de complementar as intervenções destinadas a aumentar a eficiência com outras medidas que limitam os volumes globais de consumo, salvaguardando os meios de subsistência e o bemestar humano. Com os arranjos institucionais existentes, desenvolvidos em uma era de expansão econômica contínua, a redução do consumo teria sérias consequências socioeconômicas (FREITAS, 2012).

E, embora a política ambiental possa ser feita e o Estado de Direito seja estabelecido nos níveis internacional, nacional e regional, a implementação da sustentabilidade continuará a ser uma visão de realidade nos níveis da comunidade, necessitando basicamente ser vista a partir de um processo local ou de base, pois é aqui que a resiliência será comprovada. 


\section{Considerações Finais}

A sociedade em todo o mundo enfrenta forças para um presente e futuro sustentáveis. No entanto, o mundo não está mudando no ritmo necessário, o que pode ser verificado em algumas áreas, como padrões de consumo, onde os resultados alcançados foram até agora muito modestos.

Mesmo considerando que houve evolução nas discussões sobre sustentabilidade, as linhas básicas da estrutura global permanecem inalteradas. como se pensava há vinte anos, a possibilidade de um longo prazo planetário para o desenvolvimento sustentável, exige a existência de um arranjo global eficaz, envolvendo a aplicação de tecnologias, bem como as diferentes percepções entre os países, em efetivar processos eficientes na construção de um pacto sustentável efetivo.

Nesse tema, o problema central do consumo e produção suprime a relevância pública do debate essencial sobre a sustentabilidade, políticas efetivas para a supressão da exploração do meio ambiente, decorrem muitas vezes da questão de justiça e da equidade social, na qual precisaria ser a matéria no centro do debate político; uma vez que não adota uma postura limitadora, mas sim discorre sobre as consequências das ações impensadas até hoje tomadas. Desta forma, balizando o consumo, por conseguinte reduz-se a produção e a exploração de matéria-prima, sendo uma sujeição efetiva para a sustentabilidade.

Trata-se, portanto, da compreensão de uma nova forma de consumo, que tenha perceptibilidade de que isso provocará modificações de comportamento, conduta ecológica e formas de pensar. Não se trata apenas de consumir produtos que aproveitem procedimentos menos poluentes, mas a moderação e transformação dos padrões de consumo, de maneira especial na conscientização daquilo que realmente se usa e daquilo que for essencial.

Logo, tecnologia e sustentabilidade ambiental, podem ser reforçadas mutuamente. Em uma visão de proteção ambiental, as tecnologias desempenham um papel importante na mudança do curso do crescimento econômico das nações rumo à sustentabilidade, fornecendo um modelo socioeconômico alternativo que permitirá que as gerações presentes e futuras vivam em um ambiente limpo e saudável, em harmonia com a natureza.

Assim, o presente estudo refere-se ao desenvolvimento e extensão de processos, práticas e aplicações que melhoram ou substituem a forma de produção existente, facilitando a sociedade a atender suas próprias necessidades e diminuindo substancialmente o impacto 
humano no planeta. Assim como, um dos fundamentais desafios é o de obter a mudança de hábitos, valores e costumes, muito mais do que descobrir soluções para a construção de um planeta sustentável para as gerações futuras.

\section{Referências}

BAUMAN, Zygmunt. Capitalismo parasitário: e outros temas contemporâneos. Tradução Eliana Aguiar. Rio de Janeiro: Jorge Zahar, 2010.

BECK, Ulrich. Sociedade de risco: rumo a uma outra modernidade. Tradução de Sebastião Nascimento. São Paulo: ed. 34; 2010.

BRASIL. Mundo afora- políticas de incentivo à inovação. Ministério da Educação e Cultura: Brasília, 2013.

Produção e consumo sustentáveis - consumo consciente de embalagem. Disponível em: < http://www.mma.gov.br/responsabilidade-socioambiental/producao-e-consumosustentavel/saco-e-um-saco/saiba-mais>. Acesso em: 02 dez. 2018. s/p.

CANCLINI, Nestor Garcia. Consumidores e cidadãos - conflitos multiculturais da globalização. Rio de Janeiro: EdUFRJ, 2001.

CONFERÊNCIA DAS NAÇÕES UNIDAS. La ciencia, la tecnología y la innovación como catalizadores de los objetivos de desarrollo sostenible. Ginebra, 2017, 17 p. Disponível em: < https://unctad.org/meetings/es/SessionalDocuments/ciid36_ES.pdf>. Acesso em: $02 \mathrm{dez}$. 2018.

CONTE, Isaura Isabel; BOFF, Leonir Amantino. As crises mundiais e a produção de alimentos no Brasil. Maringá, v. 35, n. 1, p. 49-59, Jan.-June, 2013.

CLARO, Priscila Borin de Oliveira. CLARO, Danny Pimentel. AMANCIO, Robson. Entendendo o conceito de sustentabilidade nas organizações. R. Adm., São Paulo, v.43, n.4, p.289-300, 2008.

DAMASCENO, Silvia Mara Bortoloto; et al. Sustentabilidade no foco da inovação. Revista Gestão Industrial, Ponta Grossa, Paraná, v. 07, n. 03: p. 120-134, 2011.

DERANI, Cristiane. Direito ambiental econômico. São Paulo: Max Limonad, 1997.

FREITAS, Juarez. Sustentabilidade, Direito ao Futuro. Belo Horizonte, Fórum, 2012. 
LEFF, Enrique. Saber ambiental: sustentabilidade, racionalidade, complexidade, poder. Tradução de Lúcia Mathilde Endlich Orth. 9. ed. Petrópolis: Vozes, 2012.

PEREIRA, Agostinho O. Koppe; CALGARO, Cleide. Desenvolvimento sustentável e o consumocentrismo: o paradoxo da modernidade. In: PEREIRA, Agostinho O. Koppe; CALGARO, Cleide; PEREIRA, Henrique M. Koppe. O consumo da sociedade moderna [recurso eletrônico]: consequências jurídicas e ambientais. Caxias do Sul, RS: Edusc, 2016.

PILAU SOBRINHO, Liton Lanes. Desafios da sustentabilidade na era tecnológica: a proteção dos direitos humanos. UNIVALI: Itajaí, Santa Catarina, 2018, 349 p.

PINTO, Marcelo de Rezende; BATINGA, Geogiana Luna. O consumo Consciente no contexto do consumismo moderno: algumas reflexões. Revista Gestão Org, Brasília, v. 14, n. 1, p. 30-43, 2016.

PORTILHO, Fátima. Sustentabilidade ambiental, consumo e cidadania. São Paulo: Ed. Cortez, 2010.

ROCHA, Cristiane Gomes da. Relações de produção, consumo e os impactos sobre o meio ambiente e a saúde. Universidade Cândido Mendes, Rio de Janeiro, 2010.

SANTOS, Milton. Técnica, espaço, tempo: globalização e meio técnico-científico informacional. São Paulo: Editora da Universidade de São Paulo, 2008.

SERRA, Maurício A; MORAES, Gustavo Inácio de. Tecnologia e sustentabilidade ambiental: desafios e possibilidades para os países periféricos. Economia \& Tecnologia - Ano 03, v. 09, p. 127- 134, Abr./Jun. 2007.

SETZER, Joana. Panorama do princípio da precaução: o direito do meio ambiente face aos novos riscos e incertezas. 2007. 155 f. Dissertação (Mestrado) - Programa de Ciência Ambiental, Universidade de São Paulo, São Paulo, 2007.

TRIGUEIRO, André (Coord.). Meio ambiente no século 21: 21 especialistas falam da questão ambiental nas suas áreas de conhecimento. Campinas, SP: Armazém do Ipê: 2008.

VOLKMER, André et al. Liberdade na era digital. Porto Alegre: Institutos de Estudos Empresariais, 2011 